\title{
Sediment dynamics of mountain streams as a function of variation in sediment deposition
}

\author{
*Ryunosuke Nakanishi, Yuki Okajima, Akira Baba, Yasuhiro Mitani, and Hiro Ikemi \\ Graduate School of Engineering, Kyushu University, Japan \\ *Corresponding author: nakanishi@doc.kyushu-u.ac.jp
}

\begin{abstract}
In Japan, the management of sediment in dam reservoirs has become challenging owing to heavy rain. Unexpected increase of sediment volume in dam reservoirs can increase flood risk owing to a rise in the level of the riverbed. It is therefore necessary to conduct sediment management to clarify the area of sediment production to control the amount of sediment transported and the timing of its movement. Sediment discharge from tributaries is often calculated based on catchment area and the deposited sediment volume already present in the dam reservoir. However, our preliminary surveys have implied that it is also necessary to consider regional geology in the evaluation of sediment transport. Moreover, variations in sediment deposition should be evaluated for each site where the geology changes.

In this study, we observe in detail changes in the riverbed in two tributaries with different regional geologies. Changes in the shape of the riverbed were analyzed from unmanned aerial vehicle observation data, following which the effects of erosion and sedimentation on the riverbed were quantitatively evaluated. Finally, sediment discharge was calculated by a one-dimensional numerical model of sediment transport. These results indicate that the tributary that is mostly composed of mudstone produced considerably more sediment than the tributary composed mainly of sandstone. This suggests that an understanding of regional geology is necessary in the evaluation of sediment dynamics and should be considered in addition to the catchment area.
\end{abstract}

Keywords: Sediment dynamics, UAV, GIS, Three-dimensional model

Paper Received: 31 Jan 2018

Paper Accepted: 8 March 2018

\section{INTRODUCTION}

Sediment problems inherent in dam reservoirs have tended to increase year by year (e.g., Guangqian, 2005; Auel, 2011; Anton, 2016). In the Mimikawa Basin of the Miyazaki Prefecture, southwest Japan, dam modification forms part of a strategy to continually remove accumulated sediment (Yoshitake, 2014). However, there are several unclear parameters such as changes in the material and morphology of the riverbed, and changes in the biological environment further downstream in the river channel owing to dam sediment reduction. Although it is necessary to evaluate these changes, a method to satisfactorily measure the amount of sediment supplied from the upper stream basin has not yet been established. The upstream catchment area is generally considered an indicator of the amount of sediment in the system (Takahashi, 2006), although variation in rainfall and consequent changes in flow rate also affect sediment discharge. Furthermore, it has recently been noted that regional geology affects sediment transport (Nakanishi, 2015). For a reasonable estimation of sediment transport, changes in the riverbed must be measured frequently after rainfall at locations characterized by different geologies.

Despite this realization, and largely owing to the high cost, such measurements of the riverbed are usually conducted only every few years. As the measurements to estimate sediment volume in reservoir, the measurements like sounding are conventionally conducted. It is therefore difficult to respond to real-time changes in rainfall, and hence recent developments in aerial photogrammetry using unmanned aerial vehicles (UAVs) may provide a new technique for river management in order to easily collect detailed information.

In this paper, a UAV survey was conducted in two branches of the Mimikawa Basin so as to acquire more accurate information regarding this mountainous basin and to develop the analytical technique in terms of topographic change. During this survey, the riverbed was regularly photographed and subjected to hydrological surveys, and its three-dimensional model and digital elevation model (DEM) were constructed. Further, a quantitative method of evaluation of the change in topography of the riverbed was examined. On the basis of the results of the riverbed observation and the hydrological survey, the amount of sediment discharge was calculated using a onedimensional numerical model for sediment transport.

\section{Study area and observation sites}

The study area was a part of the Mimikawa Basin in the Miyazaki Prefecture, two tributaries called the Kawauchi River and the Masutani River. The catchment area was $20.3 \mathrm{~km}^{2}$ in the Kawauchi River and $18.7 \mathrm{~km}^{2}$ in the Masutani River. As shown in Fig. 1, these tributaries were selected as the study area for their similar catchment area and similar direction of the river. There are slope failures in the basin, and these tributaries have the potential to contribute large-volume sediment that can flow downstream. 


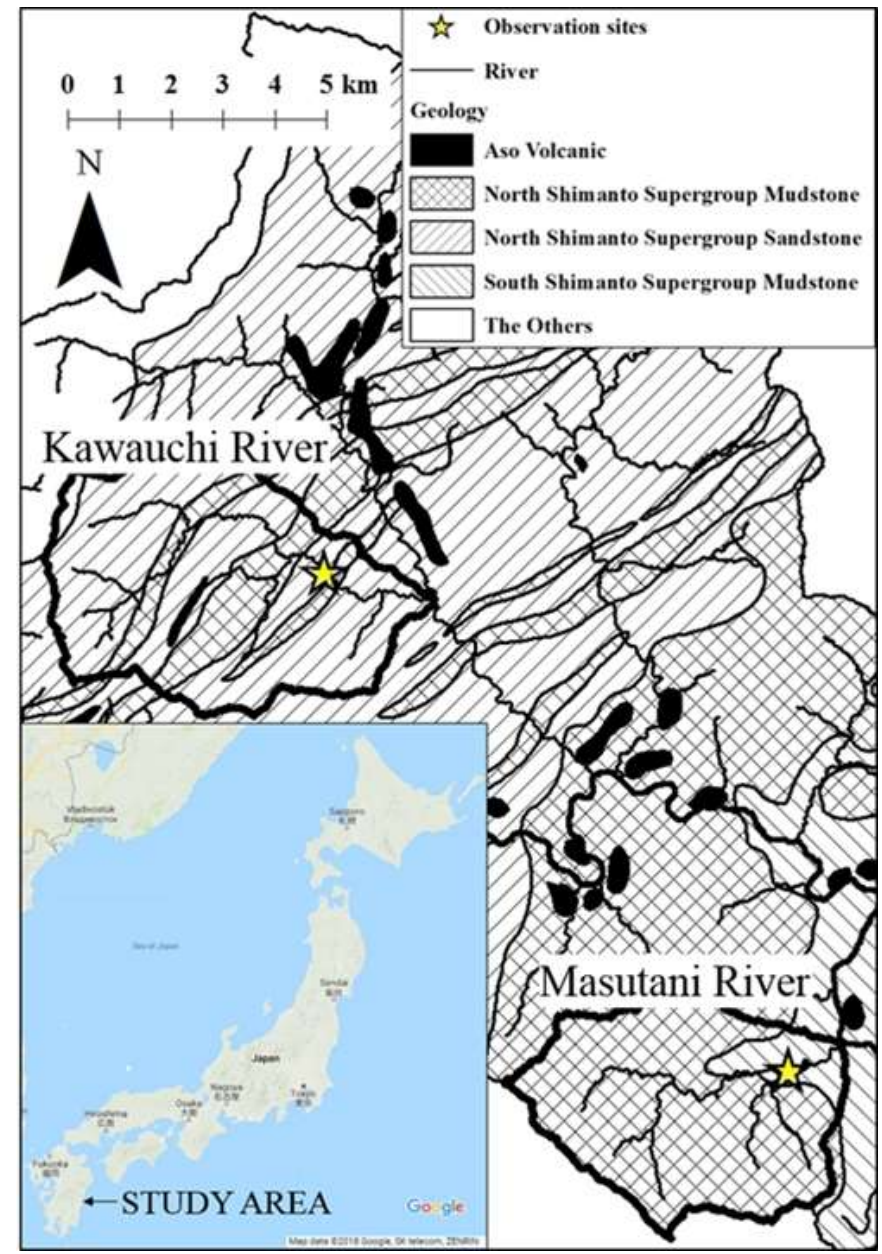

Fig. 1: Map of geological setting in study area and observation sites

The geology is mainly composed of sandstone and mudstone of the Shimanto Supergroup. It is distributed from the northeast to the southwest, and strata repeatedly crop out because of much strike faulting. The rocks become younging to the south. Preliminary surveys (Nakanishi et al., 2015) indicated that difference in regional geology was essential factor for the evaluation of sediment dynamics. Thus, the observation sites were selected to observe the riverbed between short periods, considering the regional geology of the basin. In the Kawauchi Basin, the surface geology mainly consists of the North Shimanto Supergroup sandstone together with some North Shimanto Supergroup mudstone. In the Masutani Basin, dominant rock is mudstone.

\section{METHODOLOGY}

\section{Hydrological survey}

Hydrological surveys were carried out at both sites to obtain water temperature, electrical conductivity (EC), and water level. The EC values were scaled with a YSI-Pro30 meter. The water level was continuously measured with $\mathrm{HOBO}$ pressure gauges. The water level was also converted to water discharge with the Q-L (water discharge-water level) curve made by salt dilution gauging (Day, 1977).

\section{Aerial photogrammetry using UAVs}

Deposition on the riverbed was quantitatively evaluated using UAVs. In recent UAV photography technology, it has been possible to take aerial photographs from low heights in places where it is possible to ensure against a fall of the UAV. For conventional methods, the UAV must enter the location at which riverbed measurements will be taken and must conduct this measurement several times. Terrestrial laser measurement is often used to measure structures, because the accuracy of the data is high compared with conventional methods. However, there is a possibility that the measurement device cannot be installed in a suitable position owing to the steep terrain surrounding mountainous streams. In such places, UAVs are possible to shoot an object in a short time without entering dangerous area. Changes to the riverbed are observed as threedimensional data from photographed images. Examples of aerial photogrammetry using UAVs are increasing because the economic efficiency and mobility of UAVs are excellent in small-range surveys. The accuracy of aerial photogrammetry using our UAV is approximately $25-40 \mathrm{~mm}$ when the height of the UAV is less than $50 \mathrm{~m}$ (Oishi, 2015).

\section{Evaluation of sediment deposition}

The three-dimensional model was constructed using the structure from motion (SfM) technique. SfM is one of the techniques used for 3-D image reconstruction, and multiple 2$\mathrm{D}$ images are needed as input (Mauren et al., 2015). The scheme of three-dimensional model construction refers to the previous utilization of SfM (e.g., Obanawa et al., 2014; Uchiyama et al., 2014; Hayasaka et al., 2015; Yamamura, 2015; Sugai et al., 2017) and is shown in Fig. 2. The process of constructing the three-dimensional model in this study is as follows:

\section{Photographing by a $U A V$}

Photographing of the riverbed is conducted vertically downward using a UAV. It takes about ten minutes to photograph the riverbed once. The UAV used is a DJI Phantom 3 Professional. The camera (1/2.3"CMOS, effective pixels $12.4 \mathrm{M})$ is installed in the UAV for imaging. Then, the conditions of photography are unified to all the photographed images. The coordinate of the photographing position is recorded when imaging. However, the coordinate from this observation is not used because the accuracy of GPS information is more inaccurate than the position analysed by SfM.

\section{Photo selection}

Among the images taken, the most appropriate photographs are selected to enable the construction of a three- 


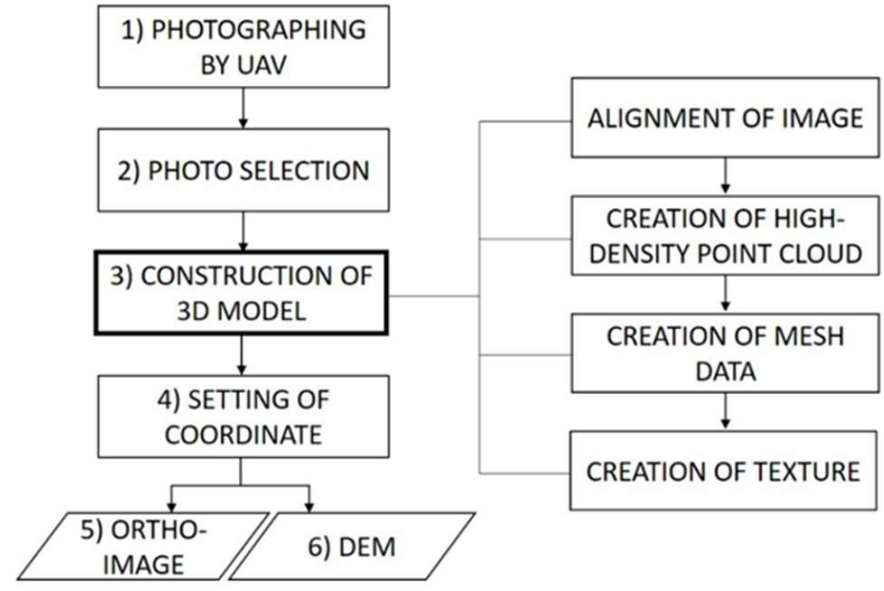

Fig. 2: Scheme of three-dimensional model construction

dimensional model. Images are not used when information has been lost because of being out-of-focus, or having crushed shadows or blown out highlights. These errors arise during image matching. Furthermore, weather is an important factor in the accuracy of SfM analysis, and therefore the photographing time is same in each survey. The number of images taken is around 600 for each observation, but the images selected for constructing the three-dimensional model total around 200 among all the images.

\section{Construction of the three-dimensional model}

As shown in Fig. 2, the process of constructing the threedimensional model can be separated into four parts, and these processes are analyzed by SfM software (Agisoft PhotoScan Professional Edition). First, alignment of images is conducted, through which the positions of the photographed images are deduced from the overlap of each image. The corresponding point cloud is created simultaneously. A point cloud is a group of points obtained by automatically extracting characteristic points; then, its characteristics are analyzed among the images of the overlapping range. Next, high-density point cloud construction is performed, a process that helps to reproduce the riverbed shape. The mesh data are a set of faces showing the surface of the terrain. Finally, textural data consist of surface colors analyzed from photographed images and their positions.

\section{Setting of coordinates}

In this experiment, it was required to set the coordinates of the three-dimensional model because the positions of images are analyzed, whereas the scale of the constructed model is not. Therefore, the ground control points (GCPs) should be measured before constructing a three-dimensional model. River structures and large stationary rocks are measured as the GCPs, and the GCPs are prepared about ten points for one three-dimensional model.

\section{Constructing the ortho-image}

The ortho-image is an image without distortion (orthorectified image) with a uniform scale over its entire surface. The ortho-image was created by processing photographed images using the function of SfM software. Also, before the creation of the ortho-image, a part of the vegetation was removed from the three-dimensional model because vegetation disturbs reconstruction of the terrain.

\section{Development of a DEM}

The three-dimensional model that was created by SfM software cannot be used as data for the riverbed variation calculation. The created model is converted to the DEM, which is available on the geographic information system (GIS), to calculate riverbed variation from UAV observation results.

\section{Calculation of riverbed variation}

Riverbed variation is calculated quantitatively based on the DEM created using GIS. GIS is a generic name for a system that manages features with location information and that can be analyzed spatially. In this study, ESRI ArcGIS for Desktop Advanced was used for the calculation. The DEM constructed from the three-dimensional model is raster data expressed as a group of grids with the same size on GIS, each of which is attributed one coordinate and a numerical value. The value of the grid is given as the average in the range of each grid, and the range of the constructed three-dimensional model is slightly different according to observation time. The common range is calculated as a condition to calculate riverbed variation, and then each observation time is calculated. Also, the average value of riverbed variation is calculated by GIS to evaluate the tendency of a change in sediment deposition in the observed area.

\section{QUANTIFICATION OF RIVERBED CHANGES}

\section{Field observations}

The sediment deposition observed on September 30, 2016, confirmed that changes in the riverbed of the Masutani River were evident (e.g., Fig. 3), and rocks of up to $50 \mathrm{~cm}$ diameter were moved. Furthermore, vegetation was removed by sediment transportation. Observations were conducted four times for each tributary on July 26, September 30, October 7 , and November 29, 2016. It was apparent that the changes from July 26 to September 30 were the most significant among the whole period of observation. On the contrary, the riverbed of the Kawauchi River changed only slightly. There are several gravels in the Kawauchi riverbed material, and these did not appear to have changed position in any observation.

\section{Differential analysis using multiple DEMs}

The three-dimensional model of each observation period was constructed according to Fig. 2 and was converted into a 

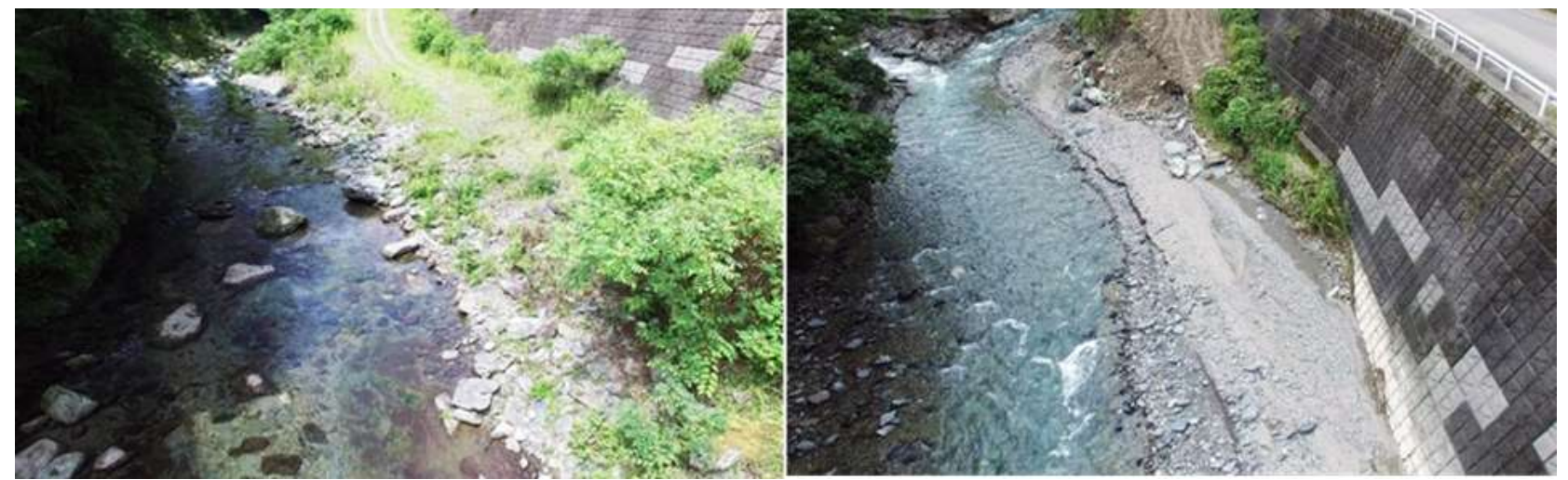

Fig. 3: Photographs of the Masutani River

DEM and an ortho-image. It is important that the accuracy of the obtained data is high in order to estimate the riverbed changes by the proposed method. Two items are considered as factors in the accuracy of the terrain data: terrain data under the water and acquisition of the coordinate.

The accuracy of terrain data under the water was verified in the observation field. Typically, terrain data under the water surface obtained by photogrammetry are underestimated owing to the refractive index of water. In general, the collective terrain data of water were multiplied by 1.34 as an adjustment for this error, and the accuracy was found to be within $1 \%$ of a previous study (Tanaka, 1975). Also, it was found that the adjustment coefficient of the refractive index is 1.33340 for freshwater at 15 degrees and 1.33985 for ocean water at 15 degrees; therefore, 1.34 is used for practical purposes (W.O.J., 1964). As a result of this verification, the accuracy of the terrain data obtained by observation was higher than that of the adjusted terrain data. Following this, the observed data without adjustment were adapted to the construction of the three-dimensional model.

The accuracy of the created DEM depends on how the coordinate is set. In our study, the coordinates were measured as GCPs by a laser distance meter (Laser Technology TruPulse 360). The accuracy of measurement of this device is $10 \mathrm{~cm}$. Also, each DEM may have an error greater than $10 \mathrm{~cm}$.

The riverbed variation was calculated by GIS and quantified based on the created DEM as shown in Figs. 4 and 5. Furthermore, the average value of sediment variation was calculated by GIS, and the results are shown in Table 1. The values in this table are the riverbed variations that were adjusted when creating the terrain data and do not include errors due to weather effects (e.g., water level and lightness). The observations on October 7 were considered to be the same as those on September 30 when calculating the riverbed variation because the riverbed changes little from September 30 to October 7, and the observation time is near. The results of the riverbed changes were $+0.09 \mathrm{~m}$ (Kawauchi River) and $-0.01 \mathrm{~m}$ (Masutani River) from September 30 to October 7. That is, the change in values was smaller than $10 \mathrm{~cm}$, and therefore the riverbed changes were considered negligible. As a result of this calculation, the tendency of the change in the Masutani River between July 26 and September 30 was a remarkable level of deposition.

\section{EVALUATION OF SEDIMENT DYNAMICS}

\section{One-dimensional numerical model}

Riverbed variation was calculated and understood from UAV observation data according to the method described above. It showed changes in the sediment deposition in a part of the tributary. However, the solution of sediment problems demands consideration of sediment dynamics, and therefore the amount of sediment flowing downstream (i.e., sediment transportation) from the observation area should be evaluated based on the riverbed variation. Then, a one-dimensional numerical model for sediment transport is used to calculate the amount of sediment discharge from the two tributaries. The numerical model was developed by the Public Works Research Institute, National Research and Development Agency of Japan. Moving sediment is classified as bedload sediment, whereas suspended sediment is classified according to its behavior (Iwagaki, 1956; Ashida et al., 1972; Shimizu et al., 1986; Inoue et al., 2002).

Numerical calculation of sediment transport requires an understanding of the shape of the river, the grain size of deposited sediment, water discharge rates, and moving sediment volume from upstream. The shape of the river is estimated by LIDAR data for the numerical model, and the accuracy of the data is $10 \mathrm{~m}$. The shape of the river is also set as several cross-sections in the numerical model and confirmed in the field. The grain size of deposited sediment is estimated from both the orthoimage and the captured sediment sample. The amount of moving sediment from upstream is given according to the observed water discharge.

\section{Simulations for sediment discharge}

The amount of sediment discharge was calculated by a one-dimensional numerical model for sediment transport, based on the average value of the riverbed variation in Table 1 and on hydrographs obtained during hydrological surveys (Figs. 6 and 7). When the first calculations were conducted, it was 


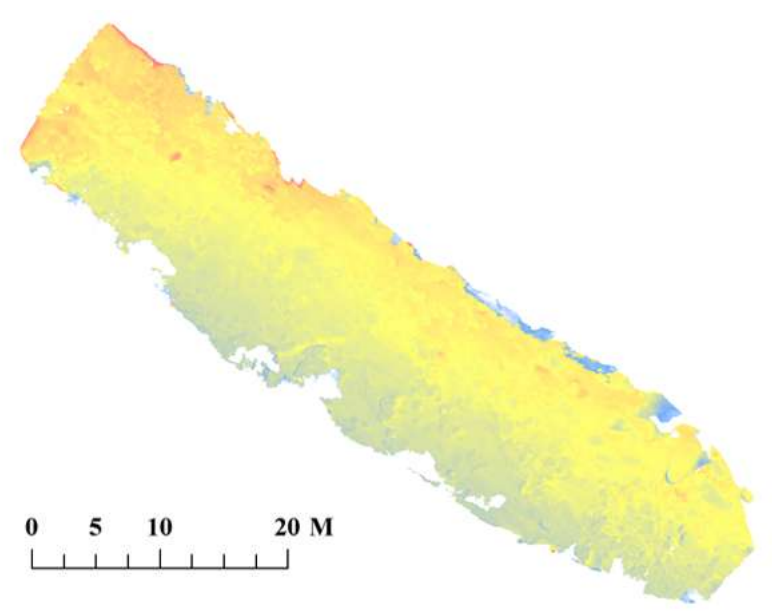

Fig. 4: Calculated riverbed variation of the Kawauchi River

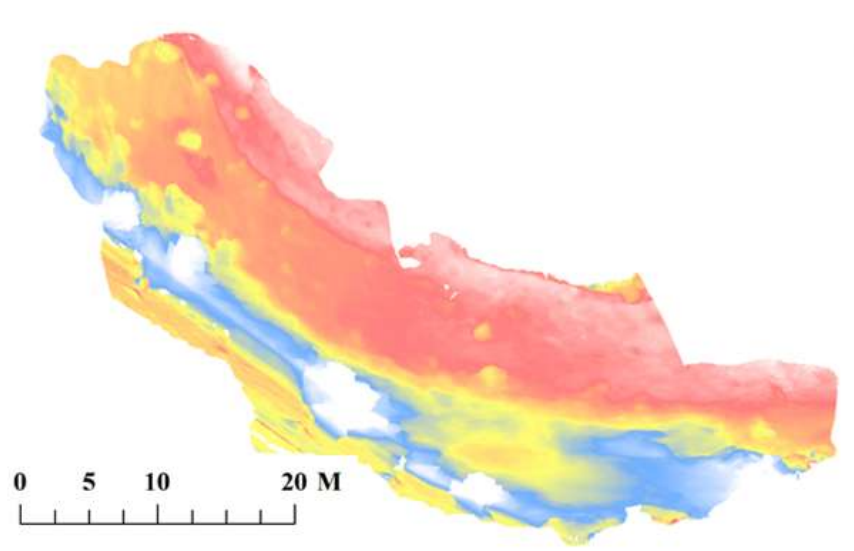

Fig. 5: Calculated riverbed variation of the Masutani River

assumed that the amount of sediment from the upper stream changes according to water flow. However, the calculated result did not support the average value of sediment variation from observation.

It was therefore considered that sediment which deposited in the river moved after September 30 without sediment supply from upstream. The two hydrographs show that several floods occurred from July 26 to September 30 and also that the water flow changed little from September 30 to November 29. The calculation based on this assumption was found to be close to the riverbed variation from observation.

The final results of the amount of sediment discharge and grain size are shown in Fig. 8. In the case of the period between July 26 and September 30, the amount of sediment discharge was $2027 \mathrm{~m}^{3}$ in the Kawauchi River and 13,010 m in the Masutani River. Also, after September 30, the amount of
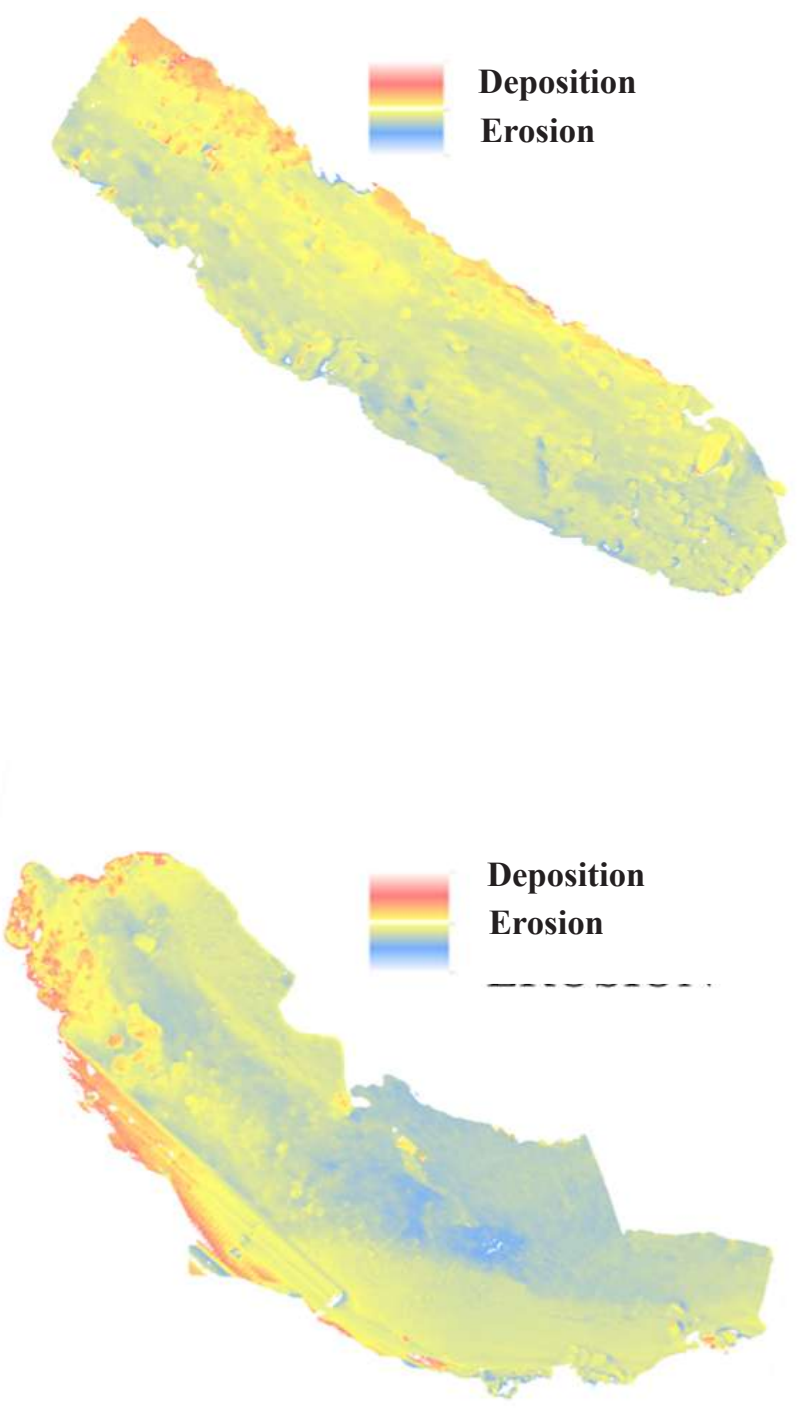

sediment discharge was almost the same in both rivers. In terms of the grain size of moving sediment, for the Kawauchi River, the observed riverbed variation matched the calculation result in that several grains of sand were contained as sediment supply. In the case of the Masutani River, when the grain size of the Kawauchi River was used to calculate, the riverbed level became low, and the result was different from the observed riverbed change. For adjustment of this difference, it was necessary to increase the proportion of sediment with a large particle size.

Table 1: Calculated average value of riverbed variation

\begin{tabular}{ccc}
\hline \multirow{2}{*}{ Site } & \multicolumn{2}{c}{ Average value of the riverbed variation (m) } \\
\cline { 2 - 3 } & July 26-September 30 & September 30-Nov 29 \\
\hline Kawauchi River & -0.2 & $-0.1>$ \\
Masutani River & +1.0 & -0.3 \\
\hline
\end{tabular}




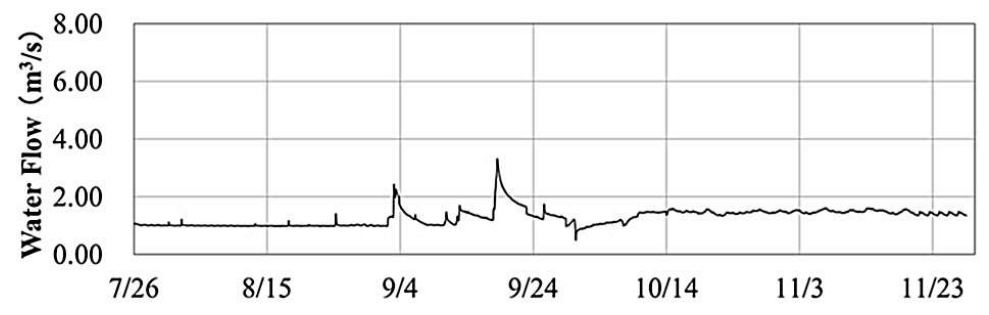

Fig. 6: Observed water flow of the Kawauchi River

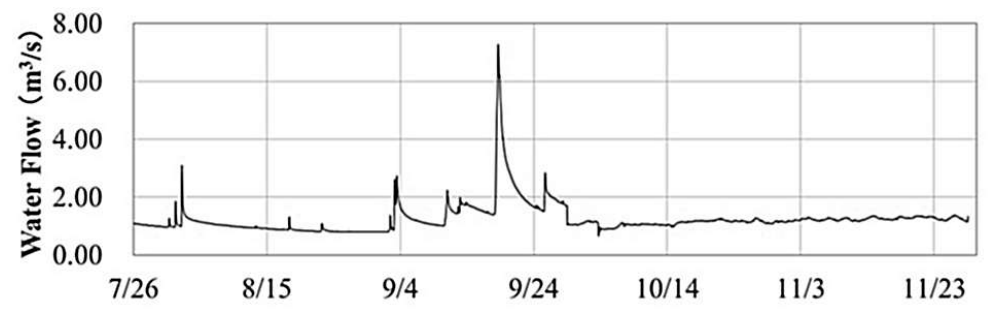

Fig. 7: Observed water flow of the Masutani River

This calculation adjustment regarding particle size was consistent with the results of the field survey and the evaluation of riverbed variation, in which the situation of sediment deposition greatly differs in both tributaries. In the Kawauchi River, sediment with grain sizes of around $2 \mathrm{~mm}$ deposited behind large rocks, and thus the riverbed changed little. Consequently, it is predicted that sediment with small grain sizes such as sand-flows out downstream. In the Masutani River, the riverbed was found to change throughout the whole area, and the positions of large rocks had also changed. Furthermore, there is evidence of slope collapse, which is plausibly a source of sediment production. According to these results, it is suggested that sediment transport is more active in rivers mainly composed of mudstone, such as the Masutani River, when compared with the Kawauchi River, which is dominantly composed of sandstone.

Our results also show that the amount of sediment discharge differs significantly between the Kawauchi and the Masutani rivers. This could mean that a difference in the regional geology influences the sediment transport. Moreover, in the case of calculations from September 30 to November 29, those without new sediment supply were more suitable for the field observation in both sites. Thus, sediment transport occurs mainly because of the flood events.

\section{CONCLUSIONS}

Sedimentation was evaluated quantitatively based on aerial photogrammetry using UAVs, including measurements of the riverbed, for two rivers. These observations were conducted in the Masutani and the Kawauchi rivers, Japan, from July to November 2016. The DEM and the three-dimensional model of the riverbed were analyzed from UAV observation data. Also, photographed images showed both sediment grain size and the nature of sediment transportation. From these observations, we suggest that the sediment from upstream passed through the observation area and moved downstream, and the riverbed situation of the Kawauchi River area was stable. In the Masutani River, large-scale sediment deposition was caused by the inflow

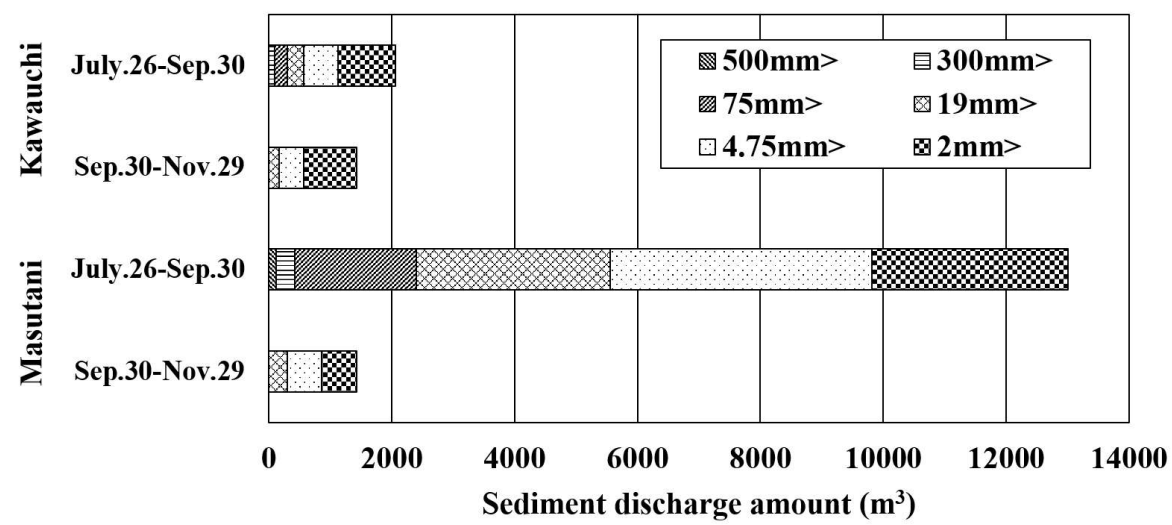

Fig. 8: Sediment discharge amount based on one-dimensional numerical modeling 
of sediment from upstream and sediment supply owing to slope collapse, and it can be assumed that sediment production and riverbed fluctuation were both active. Such information and terrain data were used as parameters for a one-dimensional numerical model of sediment transport. As a result of this calculation, the tributary that is composed of mudstone discharged considerably more sediment than that composed of sandstone. This clarifies that an understanding of regional geology is necessary to evaluate sediment dynamics rather than considering only the catchment area. Furthermore, sediment dynamics are affected by sediment production. Observation using UAVs was found to be useful for unexpected sediment production, and the amount of sediment transport was analyzed in an environment that approximates a real phenomenon.

\section{REFERENCES}

Anton, J.S., Mario, J.F., Carmel, J., and Giovanni, D.C., 2016, Reservoir sedimentation, vol. 54, pp. 595-614.

Ashida, K. and Michiue, M., 1972, Idoushou nagare no teikou to souryusharyou ni kansuru kisoteki kenkyu. (Fundamental study on resistance of moving riverbed flow and bed load transport.), Journal of JSCE, vol. 206, pp. 59-69.

Auel, C. and Boes, R.M., 2011, Sediment bypass tunnel designreview and outloo, Prod. ICOLD Symposiuym. In: A.J. Schleiss and R. M. Boes (eds.), "Dams under Changing Challenges", 79th Annual Meeting, Lucerne, Taylor and Francis, London, UK, pp.403-412.

Guangqian, W., Baosheng, W., and Zhao-Yin, W., 2005, Sedimentation problems and management strategies of Sanmenxia Reservoir, Yellow River, China, Water Resources Research, vol. 41, W09417p.

Hayasaka, H., Ohno, H., Otsuka, T., Sekiya, H., and Taki, S., 2015, Evaluation of the image-based modeling software using photographs taken from UAV, Journal of the Geospatial Information Authority of Japan, vol. 127, pp. 107-116.

Inoue, T. and Shimizu, Y., 2002, Chosuichi no suii henka wo tomonau chosuichi no haisha ni kansuru kenkyu. [Study on sediment flushing due to water level change in reservoir], Annual journal of Hydraulic Engineering, JSCE, vol.46, pp.791-795.

Iwagaki, Y., 1956, Genkai souryuuryoku no ryuutai rikigakuteki kenkyu. [Hydrodynamical study of critical tractive force], Journal of JSCE, vol.41, pp.1-21.

Mauren, A. S., Andriy, G. K., Gustavo, B. B., Tania, M. C., and Humberto, R. G., 2015, Engineering in Medicine and Biology Society (EMBC), 2015 37th Annual International Conference of the IEEE, pp.2395-2398.

Nakanishi, R., Mitani, Y., Ikemi, H., and Pachri, H., 2015, A study on the relevance of geology and sediment discharge in mountain watershed of Shimanto accretionary complex, Proc. Asian Regional Conference of IAEG, Geohazards and Engineering Geology, CDROM.

Obanawa, H., Hayakawa, Y., Saitou, H., and Gomez, C., 2014, Comparison of DSMs derived from UAV-SfM method and terrestrial laser scanning, Japan Society of Photogrammetry and Remote Sensing, vol. 53(2), pp. 67-74.

Oishi, T., Shiratani, E., Kiri, H., Takahashi, J., Mizukami, K., and Muraki, H., 2015, Research for detecting structural deterioration on sea dikes using low altitude aerial photography image analysis taken by UAV, J.JSCE, Ser.B2, Coastal engineering, vol. 71(2), pp. 1717-1722.

Shimizu, Y., Itakura, T., Kishi, T., and Kuroki, M., 1986, Shouwa 56 nen 8 gatsu kouzui ni okeru Ishikarigawa karyuubu no kashou hendou ni tsuite. [On the riverbed fluctuation in the downstream part of the Ishikari River in the flood in August 1982.], Papers on hydraulic lecture meeting, vol.30, pp.487-492.

Sugai, S., Miyaji, K., Nakamura, T., Minami, H. and Tachibana, K., 2017, Accuracy Verification of Photogrammetry using UAV, Geospatial Information Authority of Japan website.

Takahashi, T., 2006, Dosha ryuushutsu genshou to doshagai taisaku. [Sediment discharge phenomenon and provision for sediment disaster.], Kinmirai Sha.

Tanaka, K., Mori, I., Mizuno, N. and Okui, S., 1975, Water Depth Measurement Using Aerial Phtographse Shashin sokuryou to remote sensing. [Photogrammetry and Remote sensing.], vol. 14(3), pp.1-9.

Day, T.J., 1977, Filed Procedures and Evaluation of a slug dilution gauging method in mountain streams, Journal of Hydrology New Zealand, vol. 16, pp. 113-133,

Uchiyama, S., Inoue, H., and Suzuki, H., 2014, Approach for Reconstructing a Three-dimensional Model by SfM to Utilize and Apply this Model for Research on Natural Disasters, Report of the National Research Institute for Earth Science and Disaster Prevention, pp. 37-60.

W.O.J. Groeneveld Meijer C., 1964, Formula for Conversion Stereoscopically Observed Apparent Depth of Water to True DepthCNumerical Examples and DiscussionCPhotogrammetric Engineering. vol. 30, no. 6. pp. 137-145.

Yamamura, M., 2015, UAV kuusatsu gazou to SfM de kouchiku sita chikei moderu no seido hyouka to tekiou jirei. [The accuracy evaluation of the created terrain model with SfM and its apprication case.], Proceedings of the symposium on high-definition topographic data, pp. 28-30.

Yoshitake, H., Yoshimura, T., and Mitani, Y., 2014, Mimikawa suikei damu tsuusa ni okeru dosha kanri no tameno chosuichi heno ryunyu dosha ryou haaku ni kansuru kenkyu [A study on measuring of the amount of sediment flowing into dam reservoir for sediment management using sediment removal system in Mimikawa basin], Electric power civil engineering, vol, 373, pp. 28-32. 
